http://dx.doi.org/10.5007/1981-1322.2014v9n1p139

\title{
Percepções de professores que lecionam Matemática sobre a Educação Inclusiva
}

\author{
Perceptions of teachers who teach Mathematics on Inclusive Education
}

\author{
Silvia Cristina Ravasio Vasconcelos \\ silviacrvasconcelos@hotmail.com
}

Ana Lucia Manrique

analuciamanrique@hotmail.com

\begin{abstract}
Resumo
O presente trabalho identifica percepções de professores que lecionam Matemática a respeito da inserção de alunos com deficiência em sala de aula regular. Foi utilizado como instrumento de pesquisa um questionário com participação de 197 professores do estado de São Paulo. Os dados foram analisados por meio de uma estatística descritiva e uma multidimensional. Os resultados apontam que a maior parte dos professores respondentes não teve em sua formação inicial, nem continuada, um trabalho efetivo relativo à educação especial. Identificou-se também que na maior parte das escolas dos professores não há tecnologia assistiva e materiais didáticos para o trabalho com alunos com deficiência e, quando há, são insuficientes. Os professores demonstraram ser favoráveis à inserção e aos benefícios que a mesma proporciona aos alunos com e sem deficiência e à comunidade escolar na qual estão inseridos, quando se trata de deficiências leves e moderadas.
\end{abstract}

Palavras-chave: Inclusão; Professores que Ensinam Matemática; Educação Básica.

\begin{abstract}
The present paper had the objective of identifying the perceptions of the teachers who teach Mathematics concerning the inclusion of students with deficiency in a regular classroom. A 197 teachers from São Paulo state answered a questionary. The data were analized through two kinds of analisys: a descriptive and a multidimensional. According to the analysis of the data we could notice that the majority of the teachers did not have in their formation an effective work related to special education. We identified that in most schools there are no assistant technology and pedagogical material for the work with students with deficiency, and when there are such things, they are not enough. The teachers were favorable to the inclusion and to the benefit that it provides to the students and to their communities when it concerns light and moderate deficiencies.
\end{abstract}

Keywords: Inclusion; Math Teachers; Basic Education.

\section{Introdução}

A Educação Inclusiva no Brasil teve como principal marco a promulgação da Constituição da República Federativa do Brasil de 1988, que prevê no artigo 208, Inciso III: “o dever 
do Estado com a educação será efetivado mediante a garantia de atendimento educacional especializado aos portadores de deficiência, preferencialmente na rede regular de ensino". A partir de então, diversas legislações foram feitas para fazer valer o que foi previsto na constituição.

A inserção de alunos com deficiência hoje é uma realidade, presente na comunidade, nas escolas e na mídia, mas nem sempre foi assim. Para ser instaurada a educação para todos prevista na legislação passou-se por várias mudanças, pautadas por diversos paradigmas. Dentre essas mudanças, verifica-se que a mais recente transição, do paradigma da integração para o da inclusão, trouxe muitas dúvidas em relação aos seus significados e pressupostos.

Apesar de ambos os paradigmas serem formas de inserção dos alunos com deficiência, eles diferem muito entre si. Sánchez (2005) salienta algumas diferenças entre os paradigmas da integração e da inclusão, dentre elas:

- Enquanto a integração é seletiva, pois espera que o aluno se adeque à escola para ser inserido na mesma, a inclusão respeita as diferenças, pois a escola inclusiva está aberta para receber todos os alunos, com deficiência ou não;

- O paradigma da integração é pautado na individualidade, centrada apenas no aluno com deficiência, já o paradigma da inclusão se pauta na comunidade e na melhoria de todos;

- A integração torna-se preconceituosa, a inclusão valoriza as diferenças.

Segundo a mesma autora, o paradigma da inclusão surgiu:

\begin{abstract}
A princípio, como uma alternativa à integração; como uma tentativa de eliminar as situações de desintegração e exclusão em que se encontravam muitos alunos nas escolas, sob o enfoque da integração. Em segundo lugar, como uma tentativa de reconstruir o enfoque deficitário individualista e médico dominante, considerando seriamente as vozes das pessoas com deficiência, e analisando as complexas relações de poder implicadas nesses controvertidos debates. E, em terceiro lugar, como uma reivindicação de que todos os alunos com ou sem necessidades educacionais especiais recebam uma educação de qualidade, nas classes comuns do sistema regular de ensino (Sánchez, 2005, p. 17).
\end{abstract}

Sendo assim, a inclusão surge para eliminar qualquer tipo de discriminação e, além disso, reivindicar um comprometimento da sociedade em se adequar para fazer valer os direitos das pessoas com deficiência. Assim, entende-se por educação inclusiva aquela reestrutura a escola para fornecer uma educação de qualidade a todos os alunos. 
Embora, nos dias atuais, a área da educação especial venha rompendo diversas barreiras em relação aos aspectos de acessibilidade e de aprendizagem, a aprendizagem que ocorre na escola, particularmente em sala de aula, ainda enfrenta grandes dificuldades, principalmente pela falta de materiais pedagógicos e de profissionais capacitados para trabalhar com alunos com necessidades educativas especiais.

Além disso, muitos professores não se sentem preparados para trabalhar nas salas de aula com a inserção de alunos com deficiência e muitos dos alunos, que hoje estão "incluídos" e frequentam as escolas, passaram de uma situação de excluídos da escola para excluídos na escola, ou seja, estão presentes nas salas de aula regulares, mas não lhe são oferecidas oportunidades de participação e aprendizagem iguais às dos demais alunos. Segundo Glat e Pletsch (2011, p. 31):

O aluno está incluído fisicamente na turma comum e pode até ter uma boa integração social com os colegas, mas fica excluído do processo de ensinoaprendizagem. Nessa lógica, tem acesso ao sistema escolar, mas é excluído da construção do conhecimento, o que significa que estão sendo produzidas novas formas de exclusão no interior da própria escola.

O descompasso entre o que é previsto pelas políticas púbicas e o que realmente está acontecendo nas escolas brasileiras é o reflexo de como foi constituído o processo de inclusão no Brasil. De acordo com Beyer (2010, p. 08):

A particularidade da experiência brasileira da integração ou inclusão escolar reside no fato de que sua história não se assentou sobre a iniciativa de pais, familiares e escolas, porém foi articulada por estudiosos da área e técnicos de secretarias. Em vez de se constituir como um movimento gradativo de decisões conjuntas entre pais e educadores, com imediata reversão em ações de implementação e adaptação das escolas e dos professores na direção do projeto inclusivo, ocorreu um movimento deslocado das bases para o topo. Assim, quando as diretrizes político-pedagógicas da educação inclusiva foram definidas, muito pouco de história concreta nas escolas, entre as famílias e educadores, no sentido de ações efetivas de integração ou inclusão escolar, Brasil afora, havia sido feito.

Além disso, entende-se que o processo de inclusão deva ser construído na comunidade escolar, segundo Mendes (2006, p. 401).

Considerando, entretanto, que o conceito de inclusão escolar é ambíguo, porque ele assume o significado dentro de contextos históricos determinados que lhe dão definição, conclui-se também que cada comunidade deve buscar a melhor forma de definir e fazer a sua própria politica de inclusão escolar, respeitando as bases históricas, legais, filosóficas, politicas e também econômicas do contexto no qual ela irá efetivar-se. 
Percebe-se, então, que novas demandas foram solicitadas para a implementação de um processo de inserção de alunos com deficiência em sala de aula regular. Entre estas demandas, que necessitam de reflexões, destacam-se três: criação de culturas inclusivas, desenvolvimento de políticas inclusivas e orquestração de práticas inclusivas (Santos, 2002).

Neste contexto, alguns pesquisadores têm tido como objeto de estudo alguns aspectos relativos à educação do aluno com deficiência. Entre elas, destacam-se as relacionadas ao que o professor sente, entende, encontra em uma sala de inclusão, sobretudo daqueles que estão inseridos na diversidade cultural de escolas públicas de ensino básico (Gomes e Rey, 2007; Marques et al, 2008), e principalmente pesquisas junto aos professores que ensinam Matemática (Moreira e Manrique, 2013).

Tais constatações remetem à seguinte questão: Quais são as percepções dos professores que ensinam Matemática a respeito da inserção de alunos com deficiência nas salas de aula regulares? Esta questão ampara-se no pressuposto que, segundo Mazzotta (2011, p. 96), “dentre os mais importantes elementos da organização da educação escolar (comum ou especial) destaca-se como fundamental o professor".

Sendo assim, o presente estudo teve como objetivo investigar a percepção de professores, que lecionam Matemática, a respeito da inserção de alunos com deficiência em salas de aula regulares de escolas públicas do estado de São Paulo. Não se focalizou em um tipo de deficiência específica, pois essa não era a questão principal do estudo, mas sim a inserção de alunos com qualquer tipo de deficiência na escola.

\section{Procedimentos metodológicos}

Para se investigar as percepções apresentadas no objetivo de pesquisa, foi utilizado como instrumento de coleta de dados um questionário com a intenção de se obter a percepção de professores da Educação Básica que ensinam Matemática sobre a inserção de alunos com deficiência em sala de aula regular.

O questionário, formado por 58 questões, abordou: a identificação do professor pesquisado e da escola onde trabalha, além do seu aceite em participar da pesquisa; as variáveis de perfil do pesquisado; seu contato com a educação especial; sua percepção sobre a inserção de alunos com deficiência, o ensino de Matemática para alunos com 
deficiência, o uso de tecnologia assistiva e sobre sua formação para trabalhar com alunos que apresentam deficiência em sala de aula regular.

Os respondentes participantes da pesquisa foram professores de escolas públicas (municipais e estaduais) que ensinam Matemática no Ensino Fundamental I, Ensino Fundamental II, Ensino Médio e Educação de Jovens e Adultos. O interesse foi o de investigar não só os professores licenciados em Matemática, mas também os professores que lecionam Matemática nos anos iniciais do ensino fundamental.

Participaram desta pesquisa 197 professores de 88 escolas pertencentes ao estado de São Paulo, sendo 135 professores da capital, 37 da grande São Paulo e 25 do interior. Em relação ao gênero, 147 (74,62\%) são mulheres e 50 (25,38\%) são homens.

Analisando a idade dos docentes, pode-se observar que 68 professores (34,52\%) têm idade entre 41 e 50 anos, $53(26,90 \%)$ têm de 31 a 40 anos, 36 (18,27\%) têm idades maiores de 51 anos, $27(13,71 \%)$ têm idade menor de 30 anos e $13(6,60 \%)$ não responderam a essa questão.

Quando questionados sobre o tempo de experiência no magistério, 58 professores $(29,44 \%)$ respondentes declararam ter mais de 20 anos de experiência, $38(19,29 \%)$ têm de 16 a 20 anos de experiência, $31(15,74 \%)$ têm de 11 a 15 anos de experiência e 35 $(17,77 \%)$ têm até 10 anos de experiência.

Considerando o estabelecimento de ensino no qual o professor pesquisado trabalha, 160 $(81,22 \%)$ declararam trabalhar em escola estadual e 37 (18,78\%) em escola municipal. Além disso, 104 professores declararam trabalhar com alunos do Ensino fundamental I ( $1^{\circ}$ ao $5^{\circ}$ ano $)$ e 102 com alunos do Ensino Fundamental II ( $6^{\circ}$ ao $9^{\circ}$ ano $)$ e Ensino Médio. Nesses números estão incluídos os professores que trabalham na Educação de Jovens e Adultos (EJA) e os que trabalham em mais de um nível de ensino.

Os dados foram coletados por meio de abordagens pessoais e via internet. E foram analisados por meio de uma análise exploratória e, em seguida, uma análise multidimensional, aliada ao software $\mathrm{CHIC}^{1}$ (Classificação Hierárquica Implicativa e Coesiva).

\footnotetext{
${ }^{1}$ O CHIC é um software que permite realizar uma análise qualitativa através da visualização das interrelações das variáveis.
} 
O software CHIC foi utilizado para identificar as relações e similaridades entre os sujeitos e suas respostas. Para tanto, dos três tratamentos de dados disponíveis no software, utilizou-se apenas o tratamento Árvore de Similaridade que, segundo Roma (2010, p. 108109), "ajuda a interpretar quais características mostram-se estatisticamente parecidas, duas a duas, por intermédio de uma hierarquia de tipologias presentes nos sujeitos da pesquisa".

A análise descritiva dos dados permitiu, por meio de cruzamento dos dados, traçar o perfil dos professores respondentes, identificar aspectos relativos à educação especial (experiência e formação) e a existência de tecnologia assistiva e materiais pedagógicos nas escolas onde trabalham, além de suas percepções em relação à inserção de alunos com deficiência em sala de aula regular.

Já a análise multidimensional permitiu fazer agrupamentos, conforme Manrique e Lasso (2008), nos quais se pode relacionar o perfil dos professores respondentes às questões que tratam de suas percepções em relação ao processo de inserção de alunos da educação especial no ensino comum.

Tais análises nos ajudaram a identificar percepções dos professores respondentes que lecionam Matemática a respeito do processo de inserção de alunos com deficiência em salas de aula regulares de escolas públicas do estado de São Paulo.

\section{Análise Descritiva - Resultados e Discussões}

Esta análise está dividida em três tópicos: aspectos relativos à educação especial; aspectos relativos à tecnologia assistiva e aos materiais didáticos e percepção dos professores respondentes à respeito da inserção de alunos com deficiência na escola.

\section{- Aspectos relativos à educação especial}

Quando questionados se já tiveram em suas salas de aula alunos com deficiência, 175 (89\%) professores declararam que sim e 22 (11\%) que não. E, apesar de já terem tido alunos com deficiência em suas salas de aula, 130 (66\%) professores declararam não ter nenhuma experiência no ensino de Matemática para esses alunos.

Observando esses dados surgem questionamentos a respeito do trabalho realizado pelo professor em sala de aula. Por exemplo, existe ensino de Matemática para esses alunos? 
Se sim, como ocorre esse ensino? Qual metodologia é utilizada? Que materiais são utilizados? E se não existe, então o que o professor trabalha com esses alunos?

Em relação ao tipo de deficiência dos alunos, os docentes respondentes declararam ter tido em sala de aula, em sua maior parte $(72,59 \%)$, alunos com deficiência intelectual, mas, também, foram apontados outros tipos de deficiência, como por exemplo, deficiência auditiva, visual, motora, surdez, cegueira, entre outras.

Dos 197 professores respondentes, a maior parte, 161 (82\%) professores, declarou ter acesso a informações sobre os tipos de deficiência que existem, mas, apesar disso, apenas 62 (31\%) participaram de algum tipo de capacitação em educação especial, 16 (8\%) declaram ter tido em sua formação inicial alguma disciplina com esse enfoque e, a maior parte, $161(82 \%)$, nunca procurou cursos voltados ao processo de inclusão durante sua trajetória profissional.

Em relação à formação inicial, é prevista por legislação ${ }^{2}$, desde 1994, que disciplinas voltadas à educação especial sejam inseridas nos cursos de licenciatura. Mas, apesar disso, não se identifica, nas respostas dos professores respondentes, o reflexo do cumprimento de tais indicações, provavelmente pelo fato de a maior parte dos respondentes ter mais de 20 anos de experiência no magistério, ou seja, se formaram provavelmente antes de 1994.

Tal constatação, juntamente com os dados apresentados, nos remete à importância da formação continuada do professor para o trabalho com alunos com deficiência e para o avanço da educação inclusiva no Brasil. Desta forma, concorda-se com Gomes e Rey (2007, p. 408) que

\footnotetext{
A necessidade de impulsionar a mudança do paradigma vivenciado nas instituições escolares deve ser compreendida na busca da reconstrução da educação e do processo educativo, não mais como foco exclusivista, mas como trajeto de inclusão e mudança do macro sistema social.
}

\section{- Aspectos relativos à tecnologia assistiva e aos materiais didáticos}

Das 88 escolas envolvidas nesta pesquisa, em apenas $17(19,31 \%)$ foram identificadas pelo professor a existência de alguma tecnologia assistiva. Dos 197 respondentes, apenas 29 professores, 14,72\%, declararam existir tecnologia assistiva (TA) em suas escolas, e, desses, apenas $8(27,58 \%)$ afirmaram que a TA é suficiente para atender os alunos com deficiência.

${ }^{2}$ Portaria n $^{\mathrm{o}} 1.793 / 94$, Decreto n ${ }^{\mathrm{o}} 3.298 / 99$ e Resolução CNE/CP n ${ }^{\mathrm{o}}$ 01/2002. 
Ao mesmo tempo em que professores das escolas declararam a existência de TA, constatou-se que outros professores, das mesmas escolas, afirmaram desconhecer a disponibilidade de qualquer uma TA.

Tais dados podem revelar, primeiramente, o desconhecimento do professor a respeito dos materiais disponíveis em sua escola, o que indica a necessidade de divulgação, pela escola, dos materiais existentes para o trabalho pedagógico do professor. Em segundo lugar, que os materiais existentes nas escolas estão disponíveis para uso apenas nas salas de recursos. Nesse caso, o professor de sala regular não tem o material disponível para seu trabalho, ou seja, há falta de materiais (MANRIQUE et al, 2012).

Mesmo com a ausência da tecnologia assistiva nas escolas, 179 professores respondentes $(90,86 \%)$ concordam ou concordam totalmente que a existência de TA na escola é útil para minimizar as dificuldades encontradas pelo aluno com deficiência e 178 (90,35\%) concordam ou concordam totalmente que seu uso pode aumentar a autoconfiança e o sentido de independência do aluno com deficiência.

Ao se analisar os dados relativos aos materiais didáticos, observa-se que, aproximadamente, $50 \%$ dos professores respondentes não conhecem nenhum tipo de material didático apropriado para o ensino de Matemática para alunos com deficiência, cerca de $80 \%$ dos professores declaram não existir tais materiais em suas escolas, e por volta de $41 \%$ nunca utilizaram nenhum dos materiais listados no questionário, tais como, ábaco, geoplano, soroban, tangran, números em braile, entre outros.

Tanto a TA quanto os materiais didáticos são extremamente importantes para o trabalho do professor em sala de aula, pois a tecnologias assistivas podem minimizar as deficiências dos alunos, como, por exemplo, um aluno com baixa visão tem sua leitura facilitada por meio do uso de uma lupa ou de um ampliador de tela. O mesmo ocorre com o uso de materiais didáticos, como, por exemplo, o uso de ábaco para auxiliar os alunos com deficiência intelectual em contagens e operações matemáticas.

Sendo assim, pode-se identificar que além da falta, ou da quantidade insuficiente, de TA e materiais didáticos nas escolas, há a falta de conhecimento dos professores em relação à existência desses materiais em suas escolas, e, também, há a falta de treinamento dos mesmos em como utilizá-los e em relação à sua importância (MANRIQUE et al, 2012). Desta forma, concorda-se com Fragoso e Casal (2012, p. 542) que os recursos materiais 
disponíveis nas escolas de ensino regular não favorecem a inclusão de alunos com deficiência ou a promovem de forma limitada.

A existência de recursos materiais e humanos é um fator decisivo para a promoção e para o sucesso do processo de inclusão de crianças com necessidades educativas especiais. A escassez desses recursos nas escolas e jardins de infância constitui sem sombra de dúvida um obstáculo ao processo de inclusão das crianças com necessidades educativas especiais. As necessidades fazem-se sentir principalmente ao nível do material informático, do material didático diverso, do material de motricidade, das barreiras arquitetônicas e também dos recursos humanos especializados e auxiliar.

\section{- Percepção dos professores respondentes a respeito da inserção}

Conforme legislação vigente (Brasil, 2013), foram utilizados os termos grave, moderado e leve para os graus de deficiência que uma pessoa pode apresentar. Assim, ao se tratar do processo de inclusão e graus de deficiência, quando se considera uma deficiência grave, 138 docentes $(70,05 \%)$ discordaram ou discordaram totalmente que a inserção de alunos, que apresentam esse grau de deficiência em classes regulares, pode ser benéfica para eles. Em contrapartida, concordaram ou concordaram totalmente com os benefícios da inclusão quando se considera um grau de deficiência moderada (119 docentes, 60,41\%) ou leve (182 docentes, 92,39\%).

Diante desses dados, verifica-se que, quando se trata de uma deficiência leve, os professores respondentes são mais favoráveis à inserção dos alunos em salas regulares do que quando se trata de uma deficiência grave. Segundo Camisão (2004, p. 123):

\footnotetext{
Algumas investigações (e.g. Scruggs \& Mastropieri, 1996), sugerem que os professores estão mais dispostos a ensinar alunos com dificuldades ligeiras, do que ensinar alunos com graves incapacidades, porque aparentemente os professores percepcionam ser necessário maiores recursos e melhores competências para conseguirem desempenhar tal tarefa.
}

Sendo assim, a educação inclusiva se torna inatingível sem a formação adequada dos professores, adequações em infraestrutura e disponibilização de tecnologia assistiva e materiais pedagógicos, pois tal educação deve-se dar sem a distinção ou exclusão de alunos, sejam eles com deficiência ou não. Portanto, identifica-se a necessidade de uma formação baseada nos pressupostos do paradigma da inclusão, no qual haja, segundo Mantoan (1993, p. 01), uma "escola (de qualidade) para todos", respeitando os "educandos em sua individualidade". 
Em relação à questão que aborda a inserção de alunos com deficiência em salas de aula regulares e seus benefícios para todos os envolvidos (comunidade escolar), a maior parte dos docentes concordou ou concordou totalmente que a inclusão de alunos com deficiência em sala de aula regular é benéfica para a comunidade (156 professores, $79,19 \%$ ), para os professores (117 professores, 59,39\%), para a família dos alunos com deficiência (161 professores, 81,73\%) e para os alunos que não apresentam deficiência (157 professores, $79,70 \%)$.

Diante dos resultados obtidos, observa-se um discurso favorável ao paradigma da inclusão. Nesse sentido, Mantoan (1993, p. 02) destaca que "a diversidade no meio social e especialmente no ambiente escolar é fator determinante do enriquecimento das trocas, dos intercâmbios intelectuais, sociais e culturais que possam ocorrer entre os sujeitos que neles interagem". Sendo assim, a inserção traz benefícios tanto para os alunos com deficiência, quanto para todas as pessoas envolvidas no processo de inclusão, seja ele escolar ou social.

Quando se questiona os professores respondentes em relação ao tipo de sala de aula no qual os alunos com deficiência devam estudar, observa-se uma contradição. Ao mesmo tempo em que a maior parte (131 professores, 66,5\%) discordou ou discordou totalmente com a separação dos alunos com deficiência em salas distintas nas escolas regulares e que concordou ou concordou totalmente (132 professores, 67\%) com a inserção desses alunos em sala de aula regular, quando são questionados em relação às classes especiais, evidencia-se uma pequena diferença, menos de $9 \%$, entre os professores que concordaram ou concordaram totalmente (90 professores, 45,69\%) e os que discordaram ou discordaram totalmente (107 professores, 54,32\%).

Essas respostas podem evidenciar o despreparo e a insegurança do professor para o trabalho com alunos com deficiência, que, com isso, acabam por considerar a classe especial mais efetiva, pois nela há um professor especialista, que pode ser considerado mais bem preparado para o trabalho pedagógico com esses alunos, principalmente quando se considera alunos com deficiência grave.

Sendo assim, avaliam-se como necessárias medidas diversas de adequação dos sistemas escolares, tais como investimento em acessibilidade arquitetônica, em materiais didáticos, em tecnologia assistiva, na contratação de intérpretes em libras, além de formações dos 
professores e da equipe escolar e da identificação das percepções dos professores sobre este processo. Pois, como afirmam Gomes e Rey (2007, p. 408),

\begin{abstract}
Ao se considerar o aluno com necessidades educacionais especiais como cidadão que possuem direitos e deveres, o enfoque social de suas vidas é mudado, e eles passam a serem considerados também produtores e reprodutores de sua realidade social a ponto de sua limitação ser caracterizada como secundaria, o que proporciona o desenvolvimento de novas relações de convivência individuais e sociais. Essa mudança de enfoque, no entanto, parece esbarrar, prioritariamente, em aspectos subjetivos que há muito delimitam e estigmatizam esses alunos.
\end{abstract}

Neste sentido, concorda-se com Toledo e Vitaliano (2012) de que o trabalho colaborativo entre professores e especialistas em educação especial favorece o processo de inclusão de alunos com deficiência no ensino regular, principalmente por considerar aspectos sociais e individuais neste trabalho.

Ao analisar os dados obtidos em relação à questão dos benefícios da inserção de alunos com deficiência em sala de aula regular pode-se constatar que a maior parte dos professores respondentes concordou ou concordou totalmente com os benefícios da inserção de alunos com deficiência: visual (133 professores, 67,51\%), auditiva (151 professores, 76,65\%), motora (147 professores, 74,61\%) e intelectual (125 professores, $63,45 \%)$.

Quando questionados em relação às deficiências como surdez e cegueira, os dados passam a ser não tão significativos. Em relação à cegueira, 92 professores $(46,77 \%)$ discordaram ou discordaram totalmente com a inserção, enquanto 103 professores $(52,28 \%)$ concordaram ou concordaram totalmente. $\mathrm{O}$ mesmo acontece em relação à surdez, em que 86 professores $(43,66 \%)$ discordaram ou discordaram totalmente com a inserção e 109 professores $(55,33 \%)$ concordaram ou concordaram totalmente.

Tais dados evidenciam mais uma vez a tendência de o professor se sentir mais confortável com a inserção quando se trata de deficiências em graus leves e moderados. O paradigma da inclusão fixa que não se pode pautar um ensino inclusivo arraigado na separação dos alunos de acordo com o grau de sua deficiência. E que a escola inclusiva deve atender a todos os alunos, com ou sem deficiência, sem exceções. Porém, nas normativas é previsto atendimento educacional especializado e ainda para casos mais graves a escola especial.

Assim, entende-se que uma escola inclusiva não se faça só com formação dos professores, mas, segundo Silva (2009, p. 151), 
sem formação que contribua para atenuar receios e mitos socialmente construídos e dê segurança relativamente a práticas que necessariamente têm de ser implementadas, dificilmente teremos uma escola para todos na sua verdadeira acepção, isto é, uma escola que responda aos seus alunos de acordo com as potencialidades e as capacidades de cada um.

Ao questionar os docentes em relação às consequências geradas pela inserção do aluno com deficiência em uma sala de aula regular, pode-se constatar que a maior parte dos professores respondentes concordaram ou concordaram totalmente que a inserção tem impacto positivo tanto no progresso escolar do aluno com deficiência (139 professores, 70,56\%), quanto na sua socialização (159 professores, 80,71\%). Além disso, discordaram ou discordaram totalmente que a inserção desses alunos é prejudicial para os alunos que não apresentam deficiência (176 professores, 89,34\%).

Tais constatações nos levam a concluir que os professores respondentes percebem nos benefícios trazidos pela inserção, mas, ao mesmo tempo, ao se olhar para as demais questões pode-se notar algumas contradições, como, por exemplo, quando se trata de deficiências graves.

Segundo Mantoan e Santos (2010, p. 07):

\begin{abstract}
A inclusão é uma inovação, cujo sentido tem sido muito polemizado e por vezes distorcido pelos mais diferentes segmentos educacionais e sociais. No entanto, inserir na escola comum alunos com problemas de toda ordem, sejam esses problemas permanentes ou temporários, mais graves ou menos severos, nada mais é do que garantir o direito de todos à educação, conforme dita a Constituição Federal de 1988. Nosso caminho em direção às escolas inclusivas envolve mudanças substanciais na própria maneira como enxergamos e conceituamos a educação. Assim, podemos focalizar o cenário educacional brasileiro diante dessas mudanças sob os ângulos: dos desafios provocados pela inclusão na educação comum e especial, incluindo a formação dos professores; das ações no sentido de superá-los; e das perspectivas que essas ações abrem à educação escolar.
\end{abstract}

Sabe-se que o caminho a ser trilhado não é o mais fácil, mas se deve ter em mente que a educação inclusiva não é um sistema educacional paralelo ou segregado, é um conjunto de recursos que a escola tem que dispor para atender à diversidade de seus alunos.

\title{
Análise multidimensional - Resultados e discussões
}

Após submeter os dados ao software CHIC (Classificação Hierárquica Implicativa e Coesiva) e obter a árvore de similaridades, observa-se a formação de dois grandes agrupamentos, que se denominam de agrupamento 1 e agrupamento 2 . A figura 1 apresenta a árvore do primeiro agrupamento. 
Figura 1 - Agrupamento 1

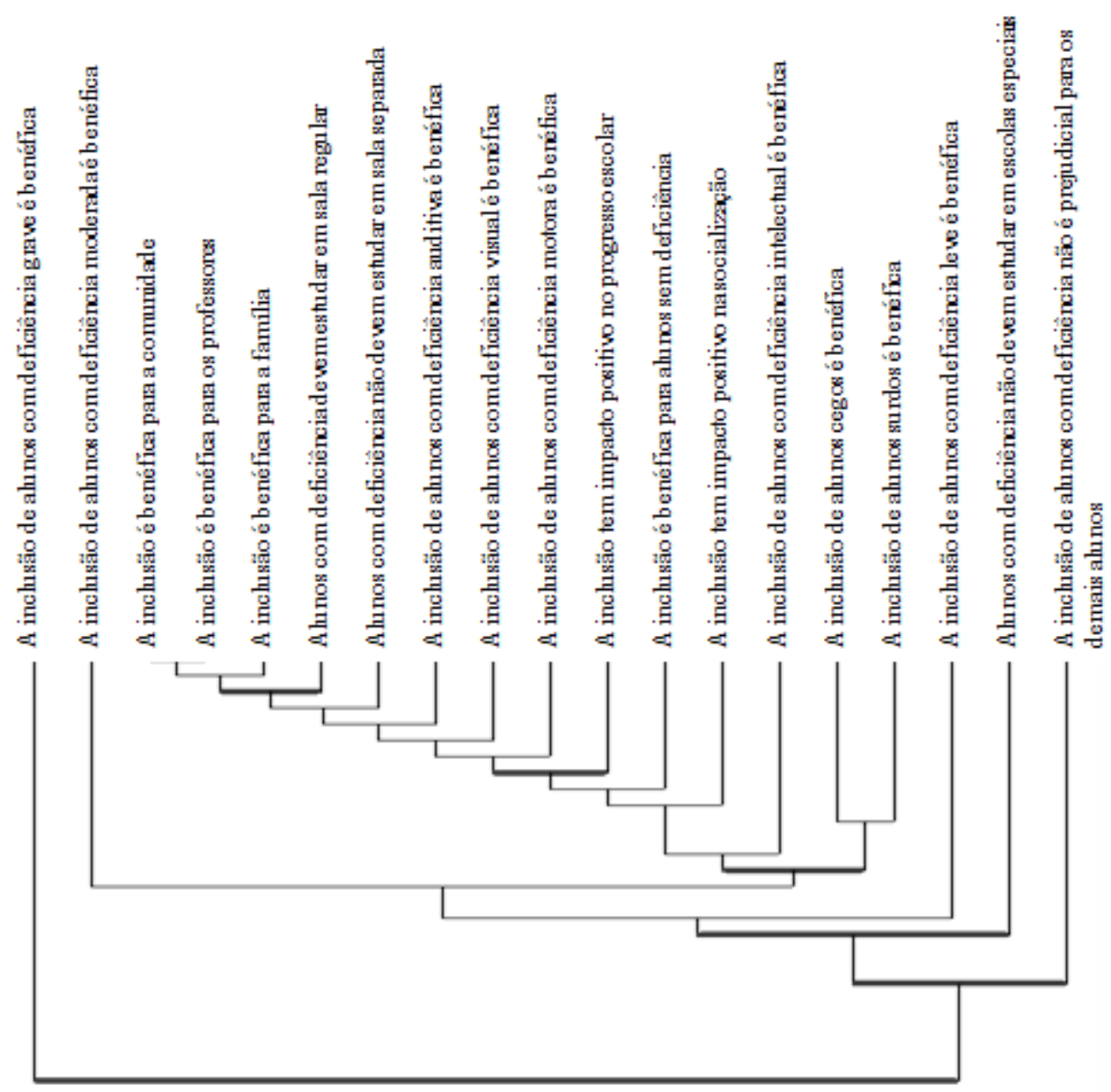

Vale lembrar que quanto mais próximo o nó (a ligação entre as variáveis) estiver da raiz da árvore de similaridades (próximo às etiquetas de identificação das variáveis), mais forte é o grau de similaridade (próximo de 1) calculado pelo software CHIC, indicando a probabilidade de que as duas variáveis ou grupos de variáveis possuam comportamentos similares quanto ao item analisado.

Os professores que lecionam matemática no Ensino Fundamental II e Médio (considerado como variável suplementar) foram os que mais contribuíram para a identificação desse agrupamento, com risco de 0,0226, e, como tal, são definidos no software CHIC como variável típica do agrupamento 1. Segundo Coutinho e Miguel (2007, p. 10), “entende-se como risco a probabilidade de se cometer um erro na afirmação feita”. Além dessa característica que se obteve, também, com um maior risco, outras variáveis suplementares que podem caracterizar esse grupo, como o gênero masculino (risco 0,109), idade de 31 a 
40 anos (risco 0,355), experiência no magistério de 16 a 20 anos (risco 0,0965) e que já tiveram alunos com deficiência em suas salas de aula (risco 0,396).

Em relação às percepções, observa-se que os professores pertencentes a esse agrupamento concordaram com:

- A existência de benefícios que a inserção de alunos com deficiência em salas de aula regulares traz para os professores e para a família desses alunos, para a comunidade no qual estão inseridos e para os alunos que não apresentam deficiência (grau de similaridade 1);

- Que os alunos com deficiência devam estudar em salas regulares e não em salas separadas ou em escolas especiais (grau de similaridade 0,99958);

- Que a inserção é benéfica para os alunos com deficiência, independente do grau de deficiência (leve, moderada ou grave) ou tipo de deficiência (intelectual, motora, auditiva, visual, cegueira ou surdez) (grau de similaridade 0,999912); e

- Que a inserção tem impacto positivo na socialização e no progresso escolar do aluno com deficiência, e não consideram que ela seja prejudicial para os demais alunos (grau de similaridade 0,998726).

Apesar de os professores respondentes que caracterizam esse agrupamento serem favoráveis à inserção, independentemente do grau de deficiência, pode-se observar na árvore de similaridades que as variáveis relativas à deficiência grave e à deficiência moderada estão em um nível maior e parecem complementar as outras variáveis. Embora a análise não tenha indicado que esse grupo de professores seja contrário à inserção, podese inferir que, quando se trata de deficiências leves ou moderadas, os professores respondentes são mais favoráveis à inserção do que quando se trata de deficiências graves. O que pode revelar a necessidade de mais recursos e formação para o desenvolvimento do trabalho dos professores junto aos alunos com deficiência (CAMISÃO, 2004; SILVA, 2009; MOREIRA, MANRIQUE, 2013).

Nesse agrupamento, cujo grau de similaridade é de 0,98382 , observa-se um discurso favorável à inserção e, sendo assim, pode-se inferir que esses professores identificam benefícios e impactos positivos para todos os envolvidos nos processo de inclusão. Para pais, professores, alunos que não apresentam deficiência e comunidade, a troca de 
experiências e a vivência com os alunos com deficiência favorecem o entendimento da inclusão e, portanto, sua implantação (SÁNCHEZ, 2005).

A figura 2 apresenta a análise do agrupamento 2 .

Figura 2 - Agrupamento 2

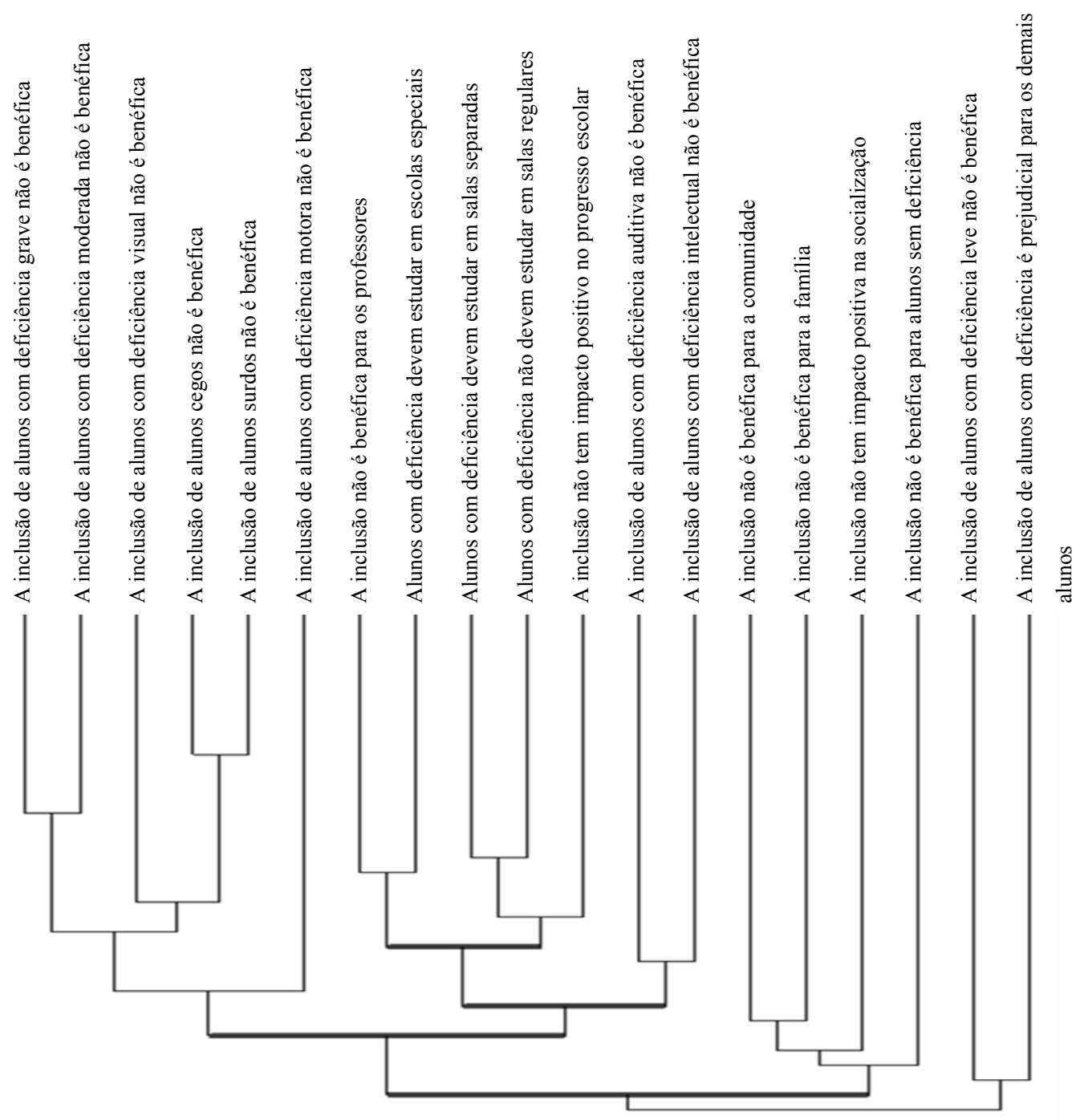

Identifica-se como variável típica do agrupamento 2 os professores que lecionam em escolas públicas municipais (considerada como variável suplementar), com risco de 0,0355. Vale destacar que, dos 197 professores respondentes, $37(18,78 \%)$ são de escolas municipais. Além dessa, e apesar de um risco maior, pode-se identificar outras variáveis suplementares como idade maior de 51 anos (risco 0,0933) e experiência no magistério de 11 a 15 anos (risco 0,0567). 
Em relação às percepções dos professores respondentes, as similaridades mais significantes nesse agrupamento 2 são as que correspondem a:

- Não considerar a inserção benéfica para os professores e concordar que ela não tem impacto positivo no progresso escolar do aluno com deficiência. Além disso, considerar que esses alunos não devem ser inseridos em salas de aula regular, ou seja, que eles devem estudar em escolas especiais ou salas separadas (grau de similaridade 0,992051); e

- Discordar que a inserção é benéfica para os alunos com deficiência visual, motora, auditiva, intelectual, quando grave e moderada, e para alunos cegos ou surdos (grau de similaridade 0,921521).

Ao analisar a árvore de similaridades desse agrupamento 2, pode-se observar que as variáveis relativas aos benefícios da inserção para a família, para a comunidade e para os alunos que não apresentam deficiência; ao impacto positivo na socialização do aluno com deficiência; aos benefícios da inserção de alunos com deficiência leve e aos prejuízos que a inserção pode trazer para os alunos que não apresentam deficiência (grau de similaridade 0,0225322) estão em um nível maior, ou seja, a ligação dessas variáveis com as demais não é tão forte e parece complementar as outras variáveis. Embora a análise não tenha indicado que esse grupo de professores seja favorável à inserção, pode-se inferir que, quando se trata de seus benefícios e da deficiência leve, essa situação poderia ser alterada se fosse oferecida formação específica em educação inclusiva para esse grupo de professores, bem como a disponibilização e capacitação para utilização de tecnologia assistiva e materiais pedagógicos apropriados para os alunos que apresentam deficiência.

Diante do apresentado, pode-se verificar que a análise multidimensional reforça o obtido na análise descritiva, ou seja, que a maior parte dos professores respondentes a esta pesquisa são favoráveis à inserção, contudo necessitam de formação para trabalhar com os alunos com deficiências moderadas ou graves (SILVEIRA, ENUMO, ROSA, 2012). Além disso, existem professores que não possuem informações suficientes para perceberem os benefícios da inserção para todos - pais, alunos e professores. 


\section{Considerações finais}

A análise descritiva dos dados mostrou que a maior parte dos professores respondentes não tem formação apropriada em educação especial, nem experiência no ensino de Matemática para alunos com deficiência.

Quando questionados em relação ao uso de tecnologia assistiva e aos materiais pedagógicos, os professores declararam que em suas escolas não existem tais materiais disponíveis para o trabalho com os alunos com deficiência, e que, além disso, nas escolas que possuem não são disponíveis para todos os alunos ou são utilizados e conhecidos por todos os professores.

Em relação à inserção, os professores respondentes são favoráveis quando se trata de deficiências leves. Quando se trata de deficiências graves, como cegueira ou surdez, observa-se uma divisão de opiniões com a maior prevalência da não concordância.

A maior parte dos participantes desta pesquisa concordou com os benefícios que a inserção de alunos com deficiência traz para a comunidade escolar, para os professores, para a família desses alunos e para os alunos que não apresentam deficiência. Também concordou que a inserção tem impacto positivo no progresso escolar e na socialização desses e não é prejudicial para os alunos que não apresentam deficiência.

Ao se trata do local de inserção dos alunos com deficiência, houve uma contradição no discurso dos professores, pois ao mesmo tempo em que concordaram com que esses alunos estudem em salas regulares, não houve uma definição em relação a existência de salas de aula especiais para os alunos com deficiência, pois os professores se dividiram entre concordar e discordar com esse tipo de inserção.

A análise multidimensional, feita com o auxílio do software CHIC, trouxe dois agrupamentos. No primeiro agrupamento, que teve como variável típica os professores que lecionam matemática no Ensino Fundamental II e Médio, as opiniões expostas são favoráveis à inserção e aos seus benefícios. Já no segundo agrupamento, que teve como variável típica os professores que trabalham em escolas municipais, as opiniões foram contrárias à inserção e aos seus benefícios.

Estes resultados apontam que são necessários mais estudos a respeito das percepções, representações, sentimentos e crenças dos professores. Segundo Gomes e Rey (2007, p. 407), 
enquanto não forem compreendidos as crenças, os desejos, as frustrações e os afetos dos professores quanto a sua ação profissional, eles não poderão a assumir o papel de educar todo e qualquer aluno e, dessa forma, a instituição escolar continuará reproduzindo o círculo cruel da diferenciação e exclusão dos alunos.

Além disso, pode-se constatar a necessidade de propostas curriculares e de formação de professores para o trabalho com alunos com deficiência, propostas e formação que devem contemplar práticas com materiais didáticos e tecnologia assistiva, troca de experiências entre professores e instituições, além de teorias e legislação existente no campo da educação inclusiva. Desta forma, concorda-se com Leite, Borelli e Martins (2013, p.82), no sentido de que:

percebe-se uma lacuna na consolidação de propostas educacionais curriculares que subsidiem alternativas e procedimentos de ensino capazes de promover a ascensão acadêmica dos alunos com deficiência, que na maioria das vezes apresentam ritmos e condições diferenciadas dos demais, fato que exigirá dos profissionais da escola a oferta de ajustes curriculares para a efetivação dos princípios das políticas públicas que normatizam a educação inclusiva

E, mais, estas propostas educacionais precisam considerar atendimentos a toda equipe escolar. Conforme Silveira, Enumo e Rosa (2012, p.704),

é preciso aumentar o contingente de profissionais que atendam as instituições escolares por meio de trabalho coerente com as demandas de alunos e da equipe escolar, a partir da compreensão da natureza social e histórica das queixas apresentadas.

Consideram-se como possíveis futuras investigações as que abordam a formação em educação inclusiva oferecida nos cursos de licenciatura, além das que contemplem as práticas inclusivas dos professores de Matemática.

\section{Referências}

BEYER, H. O. Inclusão e Avaliação na Escola. Porto Alegre: Mediação, 2010.

BRASIL. Presidência da República. Lei Complementar 142, promulgada em 8 de maio de 2013. Brasília. 2013. http://congressoemfoco.uol.com.br/noticias/lei-de-aposentadoriaespecialpara-pessoas-com-deficiencia/

BRASIL. Ministério da Educação. Constituição da República Federativa do Brasil, promulgada em 05 de outubro de 1988. Brasília: Senado Federal, 1988.

BRASIL. Ministério da Educação. Portaria no 1.793, de dezembro de 1994. Dispõe sobre a disciplina "Aspectos Ético-Políticos-Educacionais da Normalização e Integração da Pessoa Portadora de Necessidades Especiais" em cursos de instituições de ensino superior. Brasília: SEESP, dez. 2004. http://portal.mec.gov.br/seesp/arquivos/pdf/port1793.pdf 
BRASIL. Ministério da Educação. Decreto no 3.298, de 20 de dezembro de 1999. Dispõe sobre a Política Nacional para a Integração da Pessoa Portadora de Deficiência. http://www.jusbrasil.com.br/legislação/109697/decreto-3298-99

BRASIL. Ministério da Educação. Resolução CNE /CP 01, de 18 de fevereiro de 2002. Institui Diretrizes Curriculares Nacionais para a Formação de Professores da Educação Básica, em nível superior, curso de licenciatura, de graduação plena. http://portal.mec.gov.br/cne/arquivos/pdf/CP012002.pdf

CAMISÃO, I. F. F. Percepções dos professores do Ensino Básico acerca da Inclusão Educativas de alunos com necessidades educativas especiais. 2008. 169 f. Dissertação (Mestrado em Psicologia) - Universidade do Minho, Portugal, 2004. http://repositorium.sdum.uminho.pt/handle/1822/941

COUTINHO, C. Q. S.; MIGUEL, M. I. R. Análise Exploratória de Dados: um estudo diagnóstico sobre concepções de professores. In: 30 ${ }^{\mathbf{a}}$ REUNIÃO ANUAL DA ANPED, 2007, Minas Gerais. Anais... Minas Gerais: ANPEd, 2007. http://www.anped.org.br/reunioes/30ra/trabalhos/GT19-2910--Int.pdf

FRAGOSO, R. M. R. A.; CASAL, J. Representações sociais dos educadores de infância e a inclusão de alunos com necessidades educativas especiais. Revista Brasileira de Educação Especial, Marília, v. 18, n. 3, p. 527-546, 2012. http://www.scielo.br/pdf/rbee/v18n3/a11.pdf

GLAT, R.; PLETSCH, M. D. Inclusão Escolar de alunos com necessidades especiais. Rio de Janeiro: EdUERJ, 2011.

GOMES, C., REY, F.L.G.. Inclusão Escolar: Representações Compartilhadas de Profissionais da Educação acerca da Inclusão Escolar. Psicologia Ciência e Profissão, 2007, 27 (3), 406-417. http://www.scielo.br/pdf/pcp/v27n3/v27n3a04.pdf

LEITE, L. P .; BORELLI, L. M.; MARTINS, S. E. S. O. Currículo e Deficiência: análise de publicações brasileiras no cenário da educação inclusiva. Educação em Revista, Belo $\begin{array}{llllll}\text { Horizonte, } & \text { v. } 29, \quad \text { n. } 01, \quad \text { p. 63-92, } & \text { mai. }\end{array}$ http://www.scielo.br/pdf/edur/v29n1/a05v29n1.pdf

MANRIQUE, A. L.; DIRANI, E. A. T.; SLAETS, A.F.F.; AREZES, P. Dispositivos assistivos para escolas públicas: uma proposta de implementação. In: Congresso Brasileiro De Engenharia Biomédica, 23, 2012, Recife. Anais.... Recife: SBEB, 2012. v. 1. pp. 675-679.

MANRIQUE, A. L.; LASSO, A. A. Changes in expectations of students doing a mathematics teacher training program about the teaching profession. In: International Congress On Mathematical Education, 11, 2008, México. Anais.... México: ICME, 2008. http://dg.icme11.org/document/get/151

MANTOAN, M. T. E. Integração x inclusão: escola (de qualidade) para todos. Pátio Revista Pedagógica, Porto Alegre, v.2, n.5, p. 48-51, 1998. 
MANTOAN, M. T. E.; SANTOS, M. T. T. Atendimento Educacional Especializado: políticas públicas e gestão nos municípios. São Paulo: Moderna, 2010.

MARQUES, L.P. et al. Analisando as pesquisas em educação especial no Brasil. Revista Brasileira de Educação Especial, Marília, Mai./Ago. 2008, v.14, n.2, p.251-272. http://www.scielo.br/pdf/rbee/v14n2/08.pdf

MAZZOTTA, M. J. S. Educação Especial no Brasil. São Paulo: Cortez, 2011.

MENDES, E.G. A radicalização do debate sobre inclusão escolar no Brasil. Revista Brasileira de Educação, Rio de Janeiro, Set./Dez. 2006, v. 11, n. 33, p. 387-405. http://www.scielo.br/pdf/rbedu/v11n33/a02v1133.pdf

MOREIRA, G.E., MANRIQUE, A.L. Que representações professores que ensinam matemática possuem sobre o fenômeno da deficiência? In: 36 $^{\mathbf{a}}$ Reunião Anual da ANPEd. Goiânia/Goiás, 2013, p. 1-18.

ROMA, J. E. As Representações Sociais dos Alunos da Licenciatura em Matemática sobre a profissão docente. Tese (Doutorado em Educação Matemática) - Pontifícia $\begin{array}{lllll}\text { Universidade Católica } & \text { de } & \text { São } & \end{array}$ http://www.pucsp.br/pos/edmat/do/tese/jose eduardo roma. pdf

SÁNCHEZ, P. A. A Educação Inclusiva: um meio de construir escolas para todos no século XXI. Revista da Educação Especial, pp. 07-18, out. 2005. http://portal.mec.gov.br/seesp/arquivos/pdf/revistainclusao1.pdf

SILVEIRA, K. A.; ENUMO, S. R. F.; ROSA, E. M. Concepções de professores sobre inclusão escolar e interações em ambiente inclusivo: uma revisão de literatura. Revista Brasileira de Educação Especial, Marília, v. 18, n. 4, p. 695-708, 2012. http://www.scielo.br/pdf/rbee/v18n4/a11v18n4.pdf

SANTOS, M.P. Educação inclusiva: redefinindo a educação especial. Ponto de Vista,

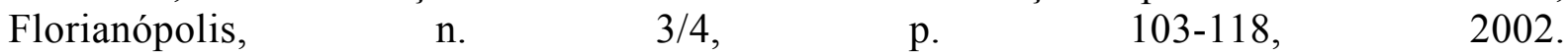
https://www.journal.ufsc.br/index.php/pontodevista/article/view/1402/1499

SILVIA, M.O.E. Da Exclusão à Inclusão: Concepções e Práticas. Revista Lusófona de Educação, 2009, n. 13, p. 135-153. http://www.scielo.oces.mctes.pt/pdf/rle/n13/13a09.pdf

TOLEDO, E. H.; VITALIANO, C. R. Formação de professores por meio de pesquisa colaborativa com vistas à inclusão de alunos com deficiência intelectual. Revista Brasileira de Educação Especial, Marília, v. 18, n. 2, p. 319-336, 2012. http://www.scielo.br/pdf/rbee/v18n2/v18n2a10.pdf 